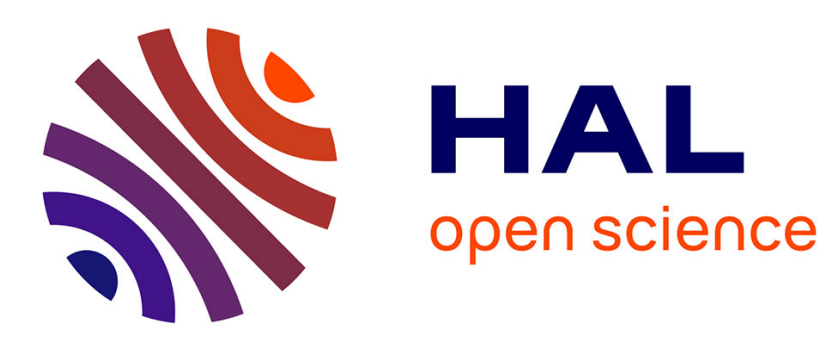

\title{
Detailed Spectrophotometric Study of Copper(I1) Halides in Anhydrous Methanol
}

\author{
M A Khan, J Meullemeestre, M J Schwing, F Vierling
}

\section{To cite this version:}

M A Khan, J Meullemeestre, M J Schwing, F Vierling. Detailed Spectrophotometric Study of Copper(I1) Halides in Anhydrous Methanol. Inorganic Chemistry, 1989, 28, pp.3306-3309. 10.1021/ic00316a011. hal-03165326

\section{HAL Id: hal-03165326 \\ https://univ-angers.hal.science/hal-03165326}

Submitted on 12 Mar 2021

HAL is a multi-disciplinary open access archive for the deposit and dissemination of scientific research documents, whether they are published or not. The documents may come from teaching and research institutions in France or abroad, or from public or private research centers.
L'archive ouverte pluridisciplinaire HAL, est destinée au dépôt et à la diffusion de documents scientifiques de niveau recherche, publiés ou non, émanant des établissements d'enseignement et de recherche français ou étrangers, des laboratoires publics ou privés. 


\title{
Detailed Spectrophotometric Study of Copper(II) Halides in Anhydrous Methanol
}

\author{
M. A. Khan, J. Meullemeestre, M. J. Schwing, and F. Vierling*
}

Received January 12, 1989

A spectrophotometric study of the copper(II) chlorides and the copper(II) bromides in anhydrous methanol was carried out at
$25^{\circ} \mathrm{C}$ and at constant ionic strength $\left(1 \mathrm{~mol} \cdot \mathrm{L}^{-1}\right)$. A matrix rank treatment of the experimental data followed by the testing of
different theoretical models confirmed the presence of four mononuclear complexes for both systems, viz. CuX
and $\mathrm{CuX} 4_{4}^{2-}$. Overall stability constants calculated for the chlorocuprates are $\beta_{1}=2.8 \times 10^{2}, \beta_{2}=1.6 \times 10^{4}, \beta_{3}=2.3 \times 10^{5}$,
and $\beta_{4}=4.5 \times 10^{5}$ and for the bromocuprates are $\beta_{1}=5.2 \times 10^{3}, \beta_{2}=3.9 \times 10^{5}, \beta_{3}=2.0 \times 10^{6}$, and $\beta_{4}=2.1 \times 10^{6}$. Individual
electronic spectra of all species in methanol are reported for the first time. In this solvent the tetracoordinated chloro complex
exhibits a calculated absorption maximum in the near-IR region consistent with a square-planar structure, in contrast to the
structure in the solid state, while for the tetrabromocuprate the structure of a flattened tetrahedron is confirmed.

\section{Introduction}

The copper(II) chlorides have been extensively studied in aqueous and nonaqueous solutions, as have the bromide complexes, although to a lesser extent. The results of studies carried out at constant ionic strength are definitely divergent, and few allusions have been made to the more highly substituted halide complexes. Even for the first complex, the overall stability constant $\beta_{1}$ for the equilibrium $\mathrm{Cu}^{2+}+j \mathrm{X}^{-} \rightleftarrows \mathrm{CuX}_{j}^{(j-2)-}$ varies in aqueous solutions, from 0.2 to 2 for the chlorides ${ }^{1-4}$ and from 0.2 to 5 for the bromides. ${ }^{1,2,5-7}$ We have already reported the results of the copper(II) chlorides and bromides at high constant ionic strength in aqueous solutions. 8.9

We recently made a new interpretation of the absorption bands observed in the UV, visible, and near-IR regions for copper(II) $-\mathrm{Na}^{+}\left(\mathrm{ClO}_{4}^{-}, \mathrm{Cl}^{-}\right) 5 \mathrm{M}$ aqueous solutions. The multiwavelength numerical treatment involving over 1000 optical density values measured in 21 solutions at 48 wavelengths demonstrated clearly the existence of four mononuclear chloro complexes as the best model. In this case the simultaneous calculation of $\beta_{j}$ is strongly dependent upon the $\beta_{1}$ value, which can range between 6 and 40 without drastic effect on the fit calculated for the $[1,2,3,4]$ model and with negligible effects on the individual calculated electronic spectra of the complexes. ${ }^{10}$

The halide complexes have also been studied in solvents such as acetone, ${ }^{11}$ acetonitrile, ${ }^{12-14}$ acetic acid, ${ }^{15-17}$ propylene carbonate, ${ }^{18}$ dimethylformamide, ${ }^{14,19,20}$ dimethyl sulfoxide, ${ }^{21-24}$ etha-

(1) Kruh, R. J. Am. Chem. Soc. 1954, 76, 4865

(2) Lister, M. W.; Rosenblum, P. Can. J. Chem. 1960, 38, 1827.

(3) Wendling, E.; Benali-Baitich, O.; Yaker, G. Rev. Chim. Miner. 1971, 8,559 .

(4) Libus, Z. Inorg. Chem. 1973, 12(12), 2972.

(5) Farigton, P. S. J. Am. Chem. Soc. 1952, 74, 966.

(6) Matsuo, S. Nippon Kagaku Zasshi 1961, 82, 1330.

(7) Watelle-Marion, G.; Keita, D. Bull. Soc. Chim. Fr. 1962, 2108.

(8) Khan, M. A.; Schwing-Weill, M. J. Inorg. Chem. 1976, 15, 2202

(9) Khan, M. A.; Schwing-Weill, M. J. Bull. Soc. Chim. Fr. 1977, 3-4, 399.

(10) Khan, M. A.; Meullemeestre, J.; Vierling, F. To be submitted for publication.

(11) Gazo, J. Chem. Zvesti 1956, 10,509.

(12) Baaz, M.; Gutmann, V.; Hampel, G.; Masaguer, I. R. Monatsh. Chem. $1962,93,1416$

(13) Manahan, S. E.; Iwamoto, R. T. I. Inorg. Chem. 1963, 4(10), 1409.

(14) Sesteli, L.; Furlani, C.; Ciana, A.; Garbassi, F. Electrochim. Acta 1970, I5, 225.

(15) Eswein, R. P.; Howald, E. S.; Howald, R. A.; Keeton, D. P. J. Inorg. Nucl. Chem. 1967, 29, 437.

(16) Sawada, K.; Ohtaki, H.; Tanaka, M. J. Inorg. Nucl. Chem. 1972, 34, 3455 .

(17) Yatsimirskii, K. B.; Mal'kova, T. V. Russ. J. Inorg. Chem. 1961, 6(4), 426.

(18) Scharff, J. P. Bull. Soc. Chim. Fr. 1972, 1, 413.

(19) Hubacek. H.: Stancie. B.: Gutmann, V. Monatsh. Chem. 1963, 94. 1118 .

(20) Katzin, L. I. J. Chem. Phys. 1962, 36(11), 3034

(21) Foll, A.; Ledemezet, M.; Courtot-Coupez, J. J. Electroanal. Chem. Interfacial Electrochem. 1972, 35, 41.

(22) Suarez, T. E.; Iwamoto, R. T.; Kleinberg, J. Inorg. Chim. Acta 1973, $7(2), 292$

(23) Libus, W.; Pilarczyk, M.; Szuchnicka, T. Electrochim. Acta 1980, 25, 1033 nol, ${ }^{25.26}$ nitromethane, ${ }^{27}$ tributyl phosphate, ${ }^{28}$ and trimethyl phosphate. ${ }^{12}$ These studies generally result in qualitative conclusions about the number and nature of the species in solution, compared in some cases to spectroscopic properties obtained in the solid state. Attempts were made in a few studies ${ }^{13,15}$ to determine the stability constants and to assign the absorption maxima of the corresponding complexes. The near-IR absorption measurements in the methanolic solutions were never used to ascertain the structural properties of these complexes.

The results of these studies concur in rather high values of stability constants in the organic medium but differ especially in the number and nature of the species present in the solution. The thermodynamic and spectroscopic properties of these complexes have been studied recently in our laboratory in some of these aprotic solvents and the results reported in the literature. ${ }^{29-32}$

This paper presents a spectrophotometric study of the copper(II) chlorides and bromides in the protic solvent anhydrous methanol. A quantitative interpretation of the complete spectral range (UV, visible, and near-IR) was carried out to determine the formation constants of the species, which were determined beforehand by a matrix rank method and the testing of different models.

The behavior of the halogeno complexes in anhydrous methanol and in water should be very similar as these two protic solvents have same donor strength and analogous dissociating power. The dielectric constant in both media remains at a level that predicts a negligible ion-pairing effect upon the equilibria and the existence of charged species. Lower hydrogen bonding in methanol should promote the substitution of the solvent molecules around the metal; consequently, greater stabilization of the copper(II) halogeno complexes will occur in anhydrous methanol compared to that in aqueous solutions.

\section{Experimental Section}

Methanol (Merck) was dried and used as solvent for the preparation of different solutions. Stock solutions of $\mathrm{LiCl}$ (Merck) and $\mathrm{LiBr}$ (Merck) at near maximum concentration of $2 \mathrm{~mol} \cdot \mathrm{L}^{-1}$ were prepared as well as that of the supporting electrolyte $\mathrm{LiClO}_{4}$ (Fluka), which was used to keep the ionic strength constant at $1 \mathrm{~mol} \cdot \mathrm{L}^{-1}$. For the copper solutions, $\mathrm{Cu}$ $\left(\mathrm{ClO}_{4}\right)_{2} \cdot 6 \mathrm{H}_{2} \mathrm{O}$ (Merck) was used to prepare a standard solution of 0.1 $\mathrm{mol} \cdot \mathrm{L}^{-1}$ concentration.

The final analytical concentration of copper was maintained at $10^{-3}$ $\mathrm{mol} \cdot \mathrm{L}^{-1}$ for the chloride as well as the bromide solutions, and the ligand

(24) Ahrland, S.; Blauenstein, P.; Tagesson, B.; Tuhtar, D. Acta Chem. Scand. 1980, A34, 265.

(25) Kosower, E. M.; Martin, R. L.; Meloche, V. M. J. Am. Chem. Soc. $1957,79,1509$

(26) Barnes, J. C.; Hume, D. N. Inorg. Chem. 1963, 2, 444

(27) Furlani, C.; Morpurgo, G. Theor. Chim. Acta 1963, 1, 102.

(28) Belousov, E. A.; Mironov, V. E.; Alavyaimikov, A. A.; Konstantinova K. K. Russ. J. Phys. Chem. 1974, 48(6), 892.

(29) Vierling, F.; Schwing, M. J.; Meullemeestre, J. Spectra 2000, 1982 $10(79)$.

(30) Elleb, M.; Meullemeestre, J.; Schwing, M. J.; Vierling, F. Inorg. Chem. $1980,19,2699 ; 1982,21,1477$

(31) Khan, M. A.; Meullemeestre, J.; Schwing, M. J.; Vierling, F. Polyhedron $1983,2(6), 459$.

(32) Amuli, C.; Meullemeestre, J.; Schwing, M. J.; Vierling, F. Inorg. Chem. 1983, 22, 3567; 1986, 25, 856; Nouv. J. Chim. 1987, 11, 27. 


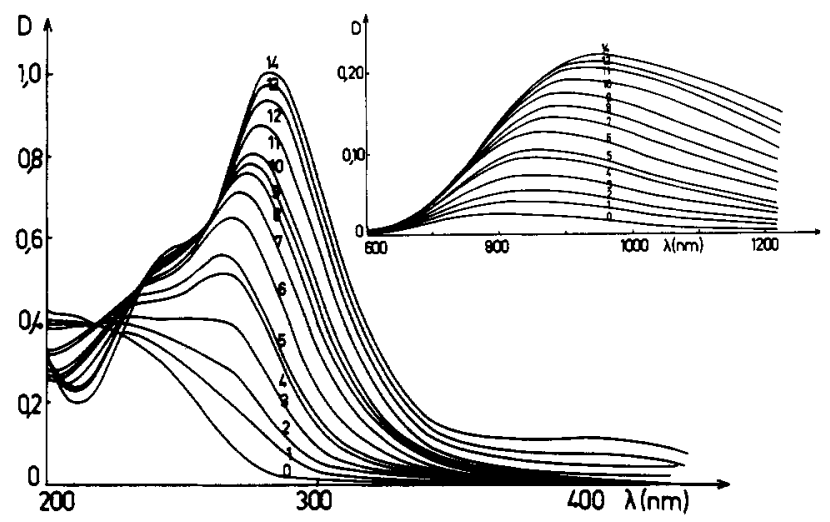

Figure 1. Absorption spectra of $\mathrm{Cu}^{\mathrm{IL}}-1 \mathrm{M} \mathrm{Li}^{+}\left(\mathrm{ClO}_{4}^{-}, \mathrm{Cl}^{-}\right)$methanolic solutions: $[\mathrm{Cu}(\mathrm{II})]=1 \times 10^{-3} \mathrm{~mol} \cdot \mathrm{L}^{-1}$; UV-visible, $l=0.2 \mathrm{~cm}$; near-IR, $l=2 \mathrm{~cm}$. Ligand concentration $C\left(\mathrm{~mol} \cdot \mathrm{L}^{-1}\right)$ : (1) 0.001 ; (2) 0.002 ; (3) 0.004 ; (4) 0.008 ; (5) $0.01 ;$ (6) 0.02 ; (7) 0.04 ; (8) 0.06 ; (9) 0.08 ; (10) 0.1 ; (11) 0.2 ; (12) 0.4 ; (13) 0.6 ; (14) 1.0 .

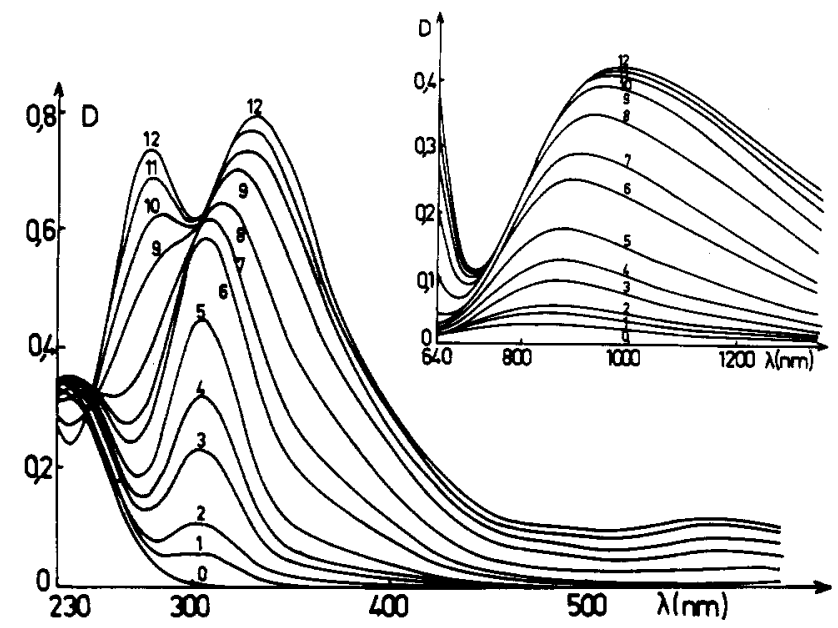

Figure 2. Absorption spectra of $\mathrm{Cu}^{\mathrm{II}}-1 \mathrm{M} \mathrm{Li}^{+}\left(\mathrm{ClO}_{4}^{-}, \mathrm{Br}^{-}\right)$methanolic solutions: $[\mathrm{Cu}(\mathrm{II})]=1 \times 10^{-3} \mathrm{~mol} \cdot \mathrm{L}^{-1}$; UV-visible, $l=0.2 \mathrm{~cm}$; near-IR, $l=2 \mathrm{~cm}$. Ligand concentration $C\left(\mathrm{~mol} \cdot \mathrm{L}^{-1}\right):$ (1) $0.001 ;$ (2) 0.002 ; (3) 0.006 ; (4) 0.01 ; (5) 0.02 ; (6) 0.06 ; (7) $0.1 ;$ (8) 0.2 ; (9) 0.4 ; (10) 0.6 ; (11) $0.8 ;(12) 1.0$.

concentrations were varied from $10^{-3}$ to $1 \mathrm{~mol} \cdot \mathrm{L}^{-1}$. The spectrum explored was from 200 to $1400 \mathrm{~nm}$. Identical solutions, without the presence of the metal, were used as spectrophotometric references to eliminate residual absorption due to the ligands, and the final solutions were prepared just before measuring the absorption. The optical densities were measured with a Cary 17D spectrophotometer equipped with digital interfacing and a Periferic Zip 30 rapid printer. The numerical analyses were performed on an IBM 3090 computer.

\section{Results and Discussion}

Experimental Spectra. The experimental spectra of the copper(II) chloride solutions and the copper(II) bromide solutions are presented in Figures 1 and 2, respectively.

For the chloride solutions a maximum at $265 \mathrm{~nm}$ with a broad shoulder between 230 and $250 \mathrm{~nm}$ appears at dilute ligand concentration. At higher chloride concentrations the maximum shifts to $285 \mathrm{~nm}$, the shoulder stabilizes at $245 \mathrm{~nm}$, and an extended absorption band appears between 350 and $450 \mathrm{~nm}$ with an intensity less than $10 \%$ of that of the main UV absorption band at $285 \mathrm{~nm}$. In the near-IR region the absorption is regular and shifts from 790 to $980 \mathrm{~nm}$. The formation of chloro complexes is characterized by small and regular shifts of an envelope absorption band without well-separated maxima; this experimental evidence renders difficult the multiwavelength numerical analysis of this system. In the case of the methanolic solutions, attention is drawn to the similarity of the absorption curves to those observed for the chloride aqueous solutions, ${ }^{10}$ with a more intense absorption band at $400 \mathrm{~nm}$ in the case of the methanolic solutions.

For the bromide solutions an absorption peak is observed that splits into two clear maxima at 275 and $330 \mathrm{~nm}$ at higher con-
Table I. Results of the Numerical Analysis of the Theoretical Models for the Copper(II) Chloride and Bromide Solutions

\begin{tabular}{ccc}
\hline & \multicolumn{2}{c}{ models } \\
\cline { 2 - 3 }$\left[\begin{array}{c}\text { Chloro Complexes } \\
\text { [1,2,3] }\end{array}\right.$ & \multicolumn{1}{c}{$(2,3,4]$} \\
$\beta_{1}$ & $(2.2 \pm 0.2) \times 10^{2}$ & $(2.8 \pm 0.8) \times 10^{2}$ \\
$\beta_{2}$ & $(3.5 \pm 0.7) \times 10^{3}$ & $(1.6 \pm 0.6) \times 10^{4}$ \\
$\beta_{3}$ & $(3.8 \pm 5.1) \times 10^{3}$ & $(2.3 \pm 1.0) \times 10^{5}$ \\
$\beta_{4}$ & \multicolumn{2}{c}{$(4.5 \pm 4.1) \times 10^{5}$} \\
$\langle\sigma\rangle$ & 0.0334 & 0.0291 \\
\multicolumn{3}{c}{ Bromo Complexes } \\
$\beta_{1}$ & $(1.2 \pm 0.3) \times 10^{2}$ & $(5.2 \pm 1.9) \times 10^{3}$ \\
$\beta_{2}$ & $(6.6 \pm 5.1) \times 10^{2}$ & $(3.9 \pm 1.1) \times 10^{5}$ \\
$\beta_{3}$ & $(7.6 \pm 6.3) \times 10^{2}$ & $(2.0 \pm 1.3) \times 10^{6}$ \\
$\beta_{4}$ & \multicolumn{2}{c}{$(2.1 \pm 1.4) \times 10^{6}$} \\
$\langle\sigma\rangle$ & 0.0466 & 0.0341
\end{tabular}

centrations. In the visible region a large band appears at $570 \mathrm{~nm}$ for solutions with $C>0.2 \mathrm{~mol} \cdot \mathrm{L}^{-1}$, while in the near-IR region the absorption of the free solvated copper ion at $790 \mathrm{~nm}$ shifts to $1060 \mathrm{~nm}$.

Although the experimental spectra of the chloro and the bromo complexes resemble each other, it is to be noted that the ratio of absorption intensity in the visible region to that in the UV region is over 0.15 for the bromides but only 0.10 for the chlorides.

Numerical Analysis. In the metal and ligand concentration ranges, only mononuclear species are formed. The determination of the overall stability constants $\beta_{j}$, corresponding to successive equilibria between $\mathrm{Cu}^{2+}$ and $\mathrm{X}^{-}$, takes into account a very large set of optical density values. Two steps characterize the mathematical treatment explained in one of our earlier publications: ${ }^{29}$ a matrix rank treatment method was used to determine the minimum number of absorbing species in the solution, ${ }^{33}$ requiring a set of $N \times L$ data, where $N$ is the number of solutions and $L$ the number of wavelengths. In the second step we use a Marquardt method ${ }^{34}$ for the calculation of the best values of $\beta_{j}$ and $\epsilon_{j}, \epsilon_{j}$ being the specific extinction coefficient of the complexes. The mathematical expression and the detailed computer program involving a novel and easily generalizable multiwavelength method, set up by two of us, will be published soon. ${ }^{35}$

The interpretation of 484 spectrophotometric data $(N=22$, $L=22$ ), both for the chloride solutions and for the bromide solutions, indicated the presence of at least three complexes in both cases. The matrix rank treatment method gives information about the presence of the minimum number of complexes only. The nature of these complexes is determined by testing different models such as $[1,2,3]$ and $[1,2,3,4]$, i.e., mono-, di-, and trihalogeno complexes and mono-, di-, tri-, and tetrahalogeno complexes. Table I summarizes the results of the numerical analysis of the two models for the two systems and gives the overall stability constants, $\beta_{j}$, of the complexes.

The standard deviations of the $\beta_{j}$ values result from the paraboloid assumption, which approximates the least-squares function to a paraboloid in the vicinity of its minimum. The deviations in $\beta_{j}$ are obtained from the elliptical intersection of the paraboloid with the plane placed at the height that corresponds to a $95 \%$ confidence interval.

The results are clearly in favor of the model with four complexes in the case of the bromide solutions, whereas for the chloride solutions this is not evident as the difference between the quadratic means $\langle\sigma\rangle$, is only 0.004 . In a situation such as this, the spectroscopic criterion in addition to the mathematical standard should be taken into account

An important factor in this type of numerical analysis is the ratio of absorption intensities in the visible and UV regions. If this ratio is about $10 \%$ or less, the results are influenced by the

(33) Hugus, Z. Z.; El Awady, A. A. J. Phys. Chem. 1971, 75(19), 2954. (34) Marquardt, D. W. An Algorithm for Least Squares Estimation of Nonlinear Parameters. J. Soc. Ind. Appl. Math. 1963, 2(2), 431.

(35) Meullemeestre, J.; Thomann, J.; Vierling, F. To be submitted for publication in Talanta. 


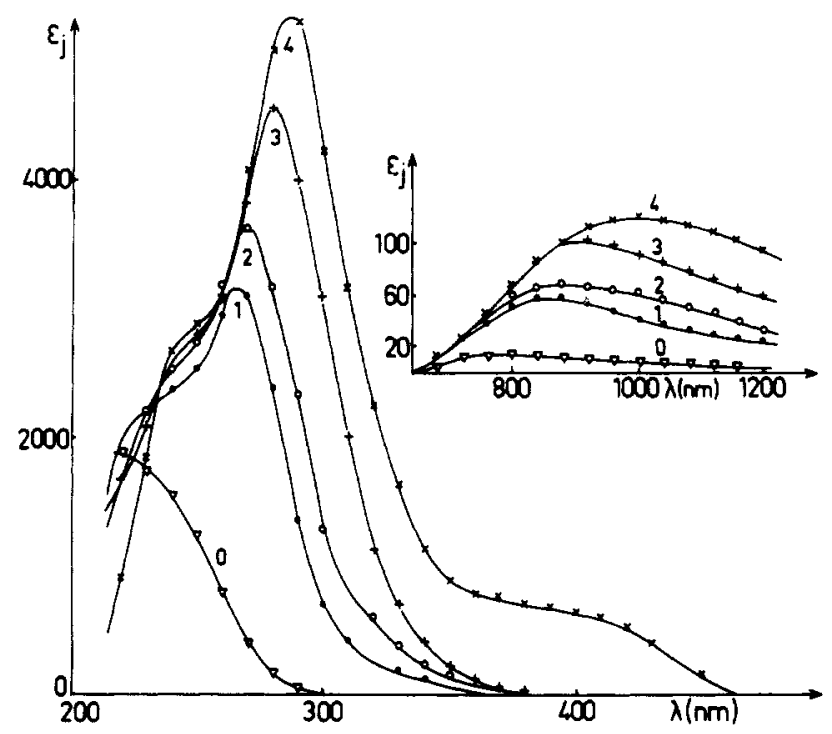

Figure 3. Calculated electronic spectra of the chlorocuprates in anhydrous methanol

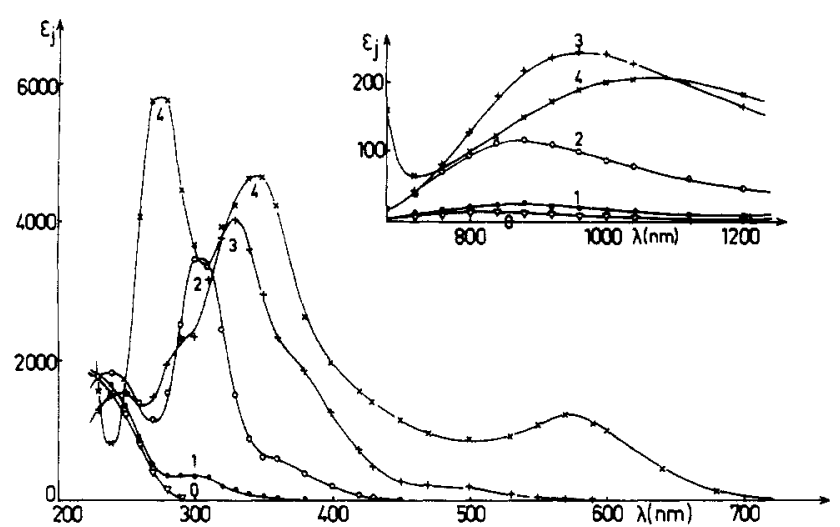

Figure 4. Calculated electronic spectra of the bromocuprates in anhydrous methanol.

selection of the $L$ wavelengths used for the optical density matrix $\left[D_{L}\right]$ for the determination of stability constants, and it is seen that only those wavelengths where the absorption is significant give satisfactory results. It is therefore important to use a matrix $\left[\mathbf{D}_{L}\right]$ that contains wavelengths where absorption is relatively higher and that corresponds to several species for a correct multiwavelength determination of the stability constants.

If the absorption ratio is about $15 \%$ or more, as is the case for the bromo complexes, different sets of matrix $\left[\mathbf{D}_{l}\right]$ values, where wavelengths have been selected in the UV, UV/vis, UV/near-IR, or UV/vis/near-IR regions, lead to approximately the same values for the stability parameters. In such cases a direct interpretation of the total experimental data can be used for the determination of $\beta$, values.

However, it is once again emphasized that the selection of the best values for the stability constants is not based entirely on a mathematical criterion ( $\langle\sigma\rangle$ should be as small as possible) but depends also on an examination of the calculated and experimental spectra.

The values of the stability constants of the copper(II) halides in methanol are much higher than those in water, which is explained by the fact that water is a strongly structured solvent and therefore renders difficult the substitution of a molecule of the solvent by that of the ligand. Furthermore, a close examination of Table I shows that in the same medium the bromides are in general more stable than the chlorides.

Electronic Spectra of the Halogenocuprates in Methanol. The calculated electronic spectra for the chloro- and the bromocuprates are presented in Figures 3 and 4, respectively.

The monochloro complex presents a charge-transfer band at $265 \mathrm{~nm}\left(\epsilon_{\max }=3160 \mathrm{~L} \cdot \mathrm{mol}^{-1} \cdot \mathrm{cm}^{-1}\right)$. Its $\mathrm{d}-\mathrm{d}$ transition band is

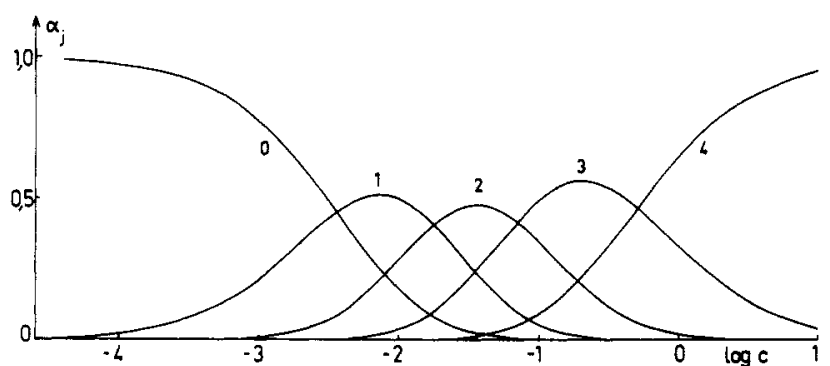

Figure 5. Formation curves of the chlorocuprates in $1 \mathrm{M} \mathrm{Li}^{+}\left(\mathrm{ClO}_{4}^{-}, \mathrm{Cl}^{-}\right)$ methanolic solutions ( $c=$ free ligand concentration).

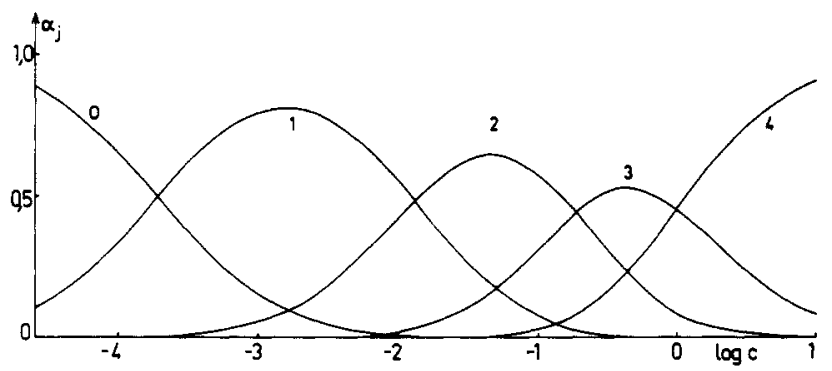

Figure 6. Formation curves of the bromocuprates in $1 \mathrm{M} \mathrm{Li}^{+}\left(\mathrm{ClO}_{4}^{-}, \mathrm{Br}^{-}\right)$ methanolic solutions ( $c=$ free ligand concentration).

situated at $860 \mathrm{~nm}$, just as that of the monobromo complex, but they differ in intensities $\left(59 \mathrm{~L} \cdot \mathrm{mol}^{-1} \cdot \mathrm{cm}^{-1}\right.$ for the former $25 \mathrm{~L}$. $\mathrm{mol}^{-1} \cdot \mathrm{cm}^{-1}$ for the latter). The monobromocuprate has its charge-transfer band at $300 \mathrm{~nm}\left(370 \mathrm{~L} \cdot \mathrm{mol}^{-1} \cdot \mathrm{cm}^{-1}\right)$. It may have another maximum of absorption in the neighborhood of $230 \mathrm{~nm}$, which could not be explicitly defined due to absorption interference of the ligand.

The dichlorocuprate has a characteristic absorption in the UV region at $270 \mathrm{~nm}\left(3420 \mathrm{~L} \cdot \mathrm{mol}^{-1} \cdot \mathrm{cm}^{-1}\right)$ with a shoulder peak at $245 \mathrm{~nm}$. In the near-IR region it absorbs at $880 \mathrm{~nm}(69) . \mathrm{CuBr}_{2}$ has an absorption maximum at $240 \mathrm{~nm}$ (1840) and another at $305 \mathrm{~nm}(3500)$. Its $\mathrm{d}-\mathrm{d}$ transition band is like that of the dichloro complex at $880 \mathrm{~nm}$, but stronger in intensity $\left(117 \mathrm{~L} \cdot \mathrm{mol}^{-1} \cdot \mathrm{cm}^{-1}\right)$.

The trichloro complex has an electronic spectrum comparable to that of $\mathrm{CuCl}_{2}$, with a shoulder peak at $245 \mathrm{~nm}$ and a maximum at $280 \mathrm{~nm}\left(4560 \mathrm{~L} \cdot \mathrm{mol}^{-1} \cdot \mathrm{cm}^{-1}\right)$; in the IR region it absorbs at 910 $\mathrm{nm}$ (102). The tribromocuprate, in contrast, has an intense nonsymmetrical absorption at $330 \mathrm{~nm}(4080)$ with shoulder peaks on both sides: 290 and $370 \mathrm{~nm}$. It has another secondary maximum in the UV region at $245 \mathrm{~nm}$ (1590), and its absorption in the near-IR region peaks out at $960 \mathrm{~nm}(242)$.

The tetrachloro complex also exhibits the shoulder peak at 245 $\mathrm{nm}$ and an intense absorption at $286 \mathrm{~nm}\left(5280 \mathrm{~L} \cdot \mathrm{mol}^{-1} \cdot \mathrm{cm}^{-1}\right)$. It has another large band at $390 \mathrm{~nm}(660)$, and its $\mathrm{d}-\mathrm{d}$ transition band is at $1000 \mathrm{~nm}(122)$. This existence of an intense UV band accompanied by two secondary absorptions at about 245 and 390 $\mathrm{nm}$ is found in methanol and aqueous solutions only. The analogy between the two solvents extends to the $d-d$ transition bands, for in both the solvents the maximum of absorption is situated well below $1100 \mathrm{~nm}$, in contrast to that calculated in other aprotic solvents such as DMF and $\mathrm{CP}^{30}$ and THF and TMP ${ }^{32}$ and also in protic acetic acid, ${ }^{31}$ where the complexes are ion pairs or ionic aggregates. ${ }^{36}$

The tetrabromocuprate has two very intense maxima in the UV region: the first at $275 \mathrm{~nm}\left(5840 \mathrm{~L} \cdot \mathrm{mol}^{-1} \cdot \mathrm{cm}^{-1}\right)$ and the second at $345 \mathrm{~nm}(4560)$. In the visible spectrum it has its very characteristic absorption at $570 \mathrm{~nm}(1240)$, and in the near-IR region its maximum is located at $1060 \mathrm{~nm}$ (203).

Formation Curves. The formation curves of the chloro- and the bromocuprates are shown in Figures 5 and 6, respectively. Whereas the chloro complexes are regularly distributed in the experimental range of the free ligand concentrations $(-3 \leq \log$

(36) Popov, A. I. In The Chemistry of Non-Aqueous Solvents; Lagowski, J. J., Ed.; Academic Press: New York, 1970; Vol. III, p 243. 
$c \leq 0$ ), the bromo complexes are characterized by a predominance of the mono- and subsequently the dibromo complex. However, whatever the range of concentrations considered, in whichever of the two systems, there is always the simultaneous presence of at least two complexes.

Structure. The tetracoordinated copper ion has been widely studied in the solid state, and a comparison can be drawn between the spectra in solid state and in solution. The tetrachlorocuprate has been found to exist as a flattened tetrahedron (symmetry $D_{2 d}$ ) or in a square-planar structure (symmetry $D_{4 h}$ ). Both of these structures have different spectra, and the differences are more pronounced in the $d-d$ transition band region. ${ }^{37}$ The form of symmetry $D_{4 h}$ presents two absorption bands in the near-IR region:

(37) Ferguson, J. J. Chem. Phys. 1964, 40, 3406 one at about $700-800 \mathrm{~nm}$ and another at about $950 \mathrm{~nm}$. The form of symmetry $D_{2 d}$, on the other hand, presents several $\mathrm{d}-\mathrm{d}$ transition bands between 1100 and $2200 \mathrm{~nm}$.

The tetrachlorocuprate, having an absorption maximum in the near-IR region at $1000 \mathrm{~nm}$, has by analogy a square-planar structure in methanol. The similarity between the two solvents methanol and water has already been referred to, and these are the only two solvents in which $\mathrm{CuCl}_{4}{ }^{2-}$ has $D_{4 h}$ symmetry. In all other solvents studied, by they protic or aprotic, ${ }^{30-32}$ its symmetry is $D_{2 d}$.

The tetrabromocuprate has never been observed in a squareplanar structure, and the results of all previous studies concerning solutions or solid state converge to attribute a $D_{2 d}$ symmetry for this ion. In methanol its absorption maximum has been calculated at $1060 \mathrm{~nm}$, which is very near $1100 \mathrm{~nm}$, and therefore it has a $D_{2 d}$ symmetry in conformity with all other studies.

Contribution from the Department of Chemistry, University of Calabria, Rende, Italy, Agricultural Chemistry Institute, University of Pisa, Pisa, Italy, Institute of Spectroscopic Technics (ITS)-CNR, Messina, Italy, and Department of Inorganic Chemistry, University of Messina, Messina, Italy

\title{
Ruthenium(II) Complexes of 3,6-Bis(2-pyridyl)pyridazine: Synthesis, Characterization, and Effect of the Nonchromophoric Ligands on the Photophysical and Photochemical Properties
}

\author{
Gianfranco Denti, ${ }^{*}$ la,b Luigina Sabatino, ${ }^{\text {la }}$ Giuseppina De Rosa, ${ }^{\text {la }}$ Antonino Bartolotta, ${ }^{\text {lc }}$ \\ Gaetano Di Marco, ${ }^{\text {lc }}$ Vittorio Ricevuto, ${ }^{1 \mathrm{~d}}$ and Sebastiano Campagna*,1d
}

\section{Received January 3, 1989}

\begin{abstract}
The synthesis and characterization of a series of novel $\mathrm{Ru}$ (II) heteroleptic complexes containing the ligand 3,6-bis(2-pyridyl)pyridazine (dppi) are reported. The absorption spectra (including their solvent dependence), luminescence spectra, luminescence decay, and photochemical reactivity of four of these complexes, containing the same chromophoric (dppi) ligand and different nonchromophoric ligands, are reported. The complexes studied are $\mathrm{Ru}(\mathrm{dppi})(\mathrm{CO})_{2} \mathrm{Cl}_{2}, \mathrm{Ru}(\mathrm{dppi})(\mathrm{CO})_{3} \mathrm{Cl}^{+}, \mathrm{Ru}(\mathrm{dppi})(\mathrm{CO})_{2-}$ $\left(\mathrm{COOC}_{2} \mathrm{H}_{5}\right) \mathrm{Cl}^{+}$, and $\mathrm{Ru}(\mathrm{dppi})\left(\eta^{6}-\mathrm{C}_{6} \mathrm{H}_{6}\right) \mathrm{Cl}^{+}$. For comparison purposes, the properties of the free ligand have also been investigated The absorption spectra of the complexes show intense ligand-centered (LC) bands in the UV region and moderately intense, broad metal-to-ligand charge-transfer (MLCT) bands at lower energies. The first three cited complexes exhibit a red shift of the lowest energy MLCT absorption bands with decreasing solvent polarity. All the complexes are luminescent in a rigid matrix at $77 \mathrm{~K}$ with a relatively long luminescence lifetime $\left(10^{-5}-10^{-4} \mathrm{~s}\right)$, and their emission spectra are structured and red-shifted about 2000 $\mathrm{cm}^{-1}$ wich respect to that of the free ligand. On the basis of these results, emission is assigned to a ${ }^{3} \mathrm{LC}$ excited state. The $\mathrm{Ru}(\mathrm{dppi})(\mathrm{CO})_{3} \mathrm{Cl}^{+}$complex exhibits a double emission in acetonitrile or dichloromethane fluid solution at room temperature, and the luminescence spectrum and lifetime indicate that the emitting levels have MLCT and LC characters. The carbonyl complexes examined are all photosensitive in fluid solution, with release of a $\mathrm{CO}$ ligand, and the photochemical quantum yields appear to be related to the energy gap between the lowest excited state(s) and the reactive metal-centered (MC) level.
\end{abstract}

\section{Introduction}

The synthesis ${ }^{2,3}$ and investigations on the chemical and physical behavior $^{3-7}$ of ruthenium(II) complexes with bipyridine-like $\mathrm{N}$-polydentate chelating ligands have attracted the attention of an increasing number of research groups in the last 15 years. In fact, as a consequence of their unique combination of ground- and excited-state properties, ${ }^{3-7}$ this class of coordination complexes has played and is still playing an important role in the development of several branches of pure and applied chemistry, such as photochemistry, photophysics, photocatalysis, electrochemistry, chemiluminescence, electrochemiluminescence, and supramolecular photochemistry. $6,8-12$

A key factor in determining the photophysical and photochemical behavior of transition-metal complexes is the relative energy of the ligand-centered, charge-transfer, and metal-centered excited states. ${ }^{6}$ This relative energy depends on the chromophoric and nonchromophoric ligands, so that, in principle, one can design complexes with the desired properties by a judicious choice and combination of the ligands.

* To whom correspondence should be addressed: G.D., University of Pisa; S.C., University of Messina.
As a part of an investigation on mono- and binuclear complexes of the above class, ${ }^{13}$ we report here the synthesis, the charac-

(1) (a) University of Calabria. (b) University of Pisa. (c) ITS-CNR, Messina. (d) University of Messina.

(2) See the following works, and the appropriate references therein: Belser, P.; von Zelewsky, A. Helv. Chim. Acta 1980, 63, 1675. Rillema, D. P.; Taghdiri, D. G.; Jones, D. S.; Keller, C. D.; Worl, L. A.; Meyer, T. J.; Levy, H. A. Inorg. Chem. 1987, 26, 578. Brewer, K. J.; Murphy, R W.; Petersen, J. D. Inorg. Chem. 1987, 26, 3376. Masschelein, A.; Kirsch-De Mesmaeker, A.- Verhoeven, C.: Nasielski-Hinkens, R. Inorg. Chim. Acta 1987, 129, L13. Akashesh, T. S.; Marji, D.; Al-Ahmed, Z. M. Inorg. Chim. Acta 1988, 141, 125. Ernst, S.; Kasack, V.; Kaim, W. Inorg. Chem. 1988, 27, 1146. Thummel, R. P.; Lefoulon, F. Chirayil, S. Inorg. Chem. 1987, 26, 3072

(3) Seddon, E. A.: Seddon, K. R. The Chemistry of Ruthenium; Elsevier: Amsterdam, 1984.

(4) Watts, R. J. J. Chem. Educ. 1983, 60, 834

(5) Meyer, T. J. Pure Appl. Chem. 1986, 58, 1193.

(6) Juris, A.; Balzani, V.; Barigelletti, F.; Campagna, S.; Belser, P.; von Zelewsky, A. Coord. Chem. Rev. 1988, 84, 85.

(7) Krause, K. Struct. Bonding 1987, 67, 1.

(8) Kalianasundaram, K. Coord. Chem. Rev. 1982, 46, 159.

(9) Balzani, V.; Bolletta, F.; Ciano, M.; Maestri, M. J. Chem. Educ. 1983 60,447

(10) Balzani, V.; Sabbatini, N.; Scandola, F. Chem. Rev. 1986, 86, 319

(11) Balzani, V., Ed. Supramolecular Photochemistry; Reidel: Dordrecht, The Netherlands, 1987 